Tropical Journal of Pharmaceutical Research April 2020; 19 (4): 745-749

ISSN: $1596-5996$ (print); 1596-9827 (electronic)

(C) Pharmacotherapy Group, Faculty of Pharmacy, University of Benin, Benin City, 300001 Nigeria.

Available online at http://www.tjpr.org

Original Research Article

http://dx.doi.org/10.4314/tjpr.v19i4.10

\title{
PSAT1 prompted cell proliferation and inhibited cell apoptosis in multiple myeloma through regulating PI3KIAKT pathway
}

\author{
Hongqing Zhu ${ }^{1,2}$, Yejun $\mathrm{Si}^{2}$, Yun Zhuang ${ }^{2}$, Meng $\mathrm{Li}^{2}$, Jianmin $\mathrm{Ji}^{3}$, Ou $\mathrm{Ji}^{2,3}$, Qun \\ Shen ${ }^{2,3 *}$ \\ ${ }^{1}$ Department of Hematology, Taizhou Hospital Affiliated to Nanjing University of Chinese Medicine, Taizhou City, Jiangsu \\ Province 225300, 'Nanjing University of Chinese Medicine, Nanjing City, Jiangsu Province 210046, ${ }^{3}$ Department of \\ Hematology, Affiliated Hospital of Nanjing University of Chinese Medicine, Nanjing City, Jiangsu Province 210029, China
}

*For correspondence: Email: QunShenkll@126.com; Tel: +86-25-86059194

Sent for review: 8 January 2019

Revised accepted: 4 February 2020

\begin{abstract}
Purpose: To identify the biological function of phosphoserine aminotransferase 1 (PSAT1) in regulating cell proliferation and apoptosis in multiple myeloma (MM).

Methods: The mRNA and protein levels of PSAT1 were determined using quantitative real-time polymerase chain reaction (PCR) and western blotting, respectively. Cell proliferation was measured using CCK-8 assay.

Results: PSAT1 mRNA and protein expression levels were significantly increased in MM cell lines when compared to control cells. Moreover, downregulation of PSAT1 inhibited MM cell proliferation and induced cell apoptosis, whereas overexpression of PSAT1 promoted MM cell proliferation and suppressed cell apoptosis. Further analysis demonstrated that the underlying mechanism was via regulation of PIJKJAKT pathway.

Conclusion: The results identified a novel role for PSAT1 in the progression of MM, which may provide a therapeutic and a new anticancer target for the therapy of MM.
\end{abstract}

Keywords: Multiple myeloma, PSAT1, Cell proliferation, PI3KJAKT pathway

\begin{abstract}
This is an Open Access article that uses a fund-ing model which does not charge readers or their institutions for access and distributed under the terms of the Creative Commons Attribution License (http://creativecommons.org/licenses/by/4.0) and the Budapest Open Access Initiative (http://www.budapestopenaccessinitiative.org/read), which permit unrestricted use, distribution, and reproduction in any medium, provided the original work is properly credited.
\end{abstract}

Tropical Journal of Pharmaceutical Research is indexed by Science Citation Index (SciSearch), Scopus, International Pharmaceutical Abstract, Chemical Abstracts, Embase, Index Copernicus, EBSCO, African Index Medicus, JournalSeek, Journal Citation Reports/Science Edition, Directory of Open Access Journals (DOAJ), African Journal Online, Bioline International, Open-J-Gate and Pharmacy Abstracts

\section{INTRODUCTION}

Multiple myeloma (MM) is considered the second most common hematological malignancy worldwide whose clinical manifestations include hypercalcemia, renal insufficiency, anemia, infection and uncontrolled proliferation of monoclonal plasma cells [1]. The incidence of $\mathrm{MM}$ is increasing remarkably; accounting for approximately $10 \%$ of all hematological cancers and $2.1 \%$ of all cancer deaths [2]. Over the past few decades, advances in diagnostic and standard therapeutic techniques, have improved the outcomes and prolonged survival of MM patients [3]. Thus, more molecular biomarkers and diagnostic targets for MM, which may be helpful in MM therapy $[4,5]$. 
Phosphoserine aminotransferase 1 is an aminotransferase that participates in serine biosynthesis and is highly expressed in various tissues such as breast and prostate $[6,7]$. Serine biosynthetic pathway has been shown to be crucial in regulating redox status, cell proliferation, and the biosynthesis of cellular components in several types of tumors, such as breast cancer $[8,9]$ and colorectal carcinoma $[10,11]$. In addition, PSAT1 has been shown to play a role in tumor cell proliferation, migration and chemo resistance, contributing to tumor progression and poor outcomes [12]. However, its biological functions in the development and progression of MM are rarely known.

In this study, the mRNA and protein expression levels of PSAT1 in MM cell lines were measured and its effects on MM cell proliferation were analyzed. The results identified a novel role of PSAT1 in the progression of MM, which may provide a therapeutic and a new anticancer target for the therapy of MM.

\section{EXPERIMENTAL}

\section{Cell lines}

Human bone marrow cell line HS-5 was purchased from COBIOER (China), and used as control cells. Multiple myeloma (MM) cell lines LP-1, NCl-H929, and U266 were obtained from Cell Bank of the Chinese Academy of Sciences (Shanghai, China). The cells were cultured in Dulbecco's Modified Eagle's medium containing $10 \%$ fetal bovine serum and penicillinstreptomycin at $37^{\circ} \mathrm{C}$ in $5 \% \mathrm{CO}_{2}$ cell incubator.

\section{RNA extraction and real-time PCR}

Total RNA was extracted from MM cell lines using the TRIzol reagent (Vazyme, Nanjing). First-strand cDNA was reverse-transcribed from RNA using a reverse transcriptase kit (Vazyme, Nanjing). Quantitative RT-PCR was performed using the SYBR Green PCR Master Mix (Takara, $\mathrm{RR} 047 \mathrm{~A})$. The relative expression of target gene transcripts was calculated using the $2^{-\triangle \Delta C t}$ method. The sequence of primers for PSAT1 were sense: 5'-GGGTAGGTCCCGTC-3' and antisense: 5'-CCAAAGCCAATTCCA-3'.

\section{Cell proliferation assay}

MM cells $\left(1 \times 10^{6}\right.$ cells $\left./ \mathrm{mL}\right)$ were seeded onto 96-well plates and cell proliferation was measured using the Cell Counting Kit-8(CCK-8, Dojindo). 10ul/well CCK-8 solution was added and cultured for 1 - $4 \mathrm{~h}$. Finally, the optical density (OD) was read using a microplate reader at $450 \mathrm{~nm}$.

\section{Cell transfection}

Vectors containing shPSAT1 or pcDNA3.1PSAT1, and control vectors were transfected into target cells and seeded into 6-well plates using the LP2000 Transfection Reagent (Thermo Fisher Scientific). The screening and subculture of successfully transfected cells were performed for subsequent analysis.

\section{Western blotting}

Cultured cells were harvested, and total protein was extracted in lysis buffer (Beyotime, China),separated by SDS-polyacrylamide gel electrophoresis, and blotted onto PVDF membranes [13]. Primary antibodies used were as follows: PSAT1, Bcl-2(CST), Bax (CST), cleaved caspase-3 and GAPDH, which were obtained from Abcam. All antibodies were diluted in $5 \%$ skim milk. The protein bands were visualized using the Tanon 5200 Western Blot System.

\section{Statistical analysis}

The data were analyzed using GraphPad 6.0 software and are presented as mean \pm SEM. Differences between groups were analyzed using unpaired Student's $t$ test. $P<0.05$ was considered statistically significant.

\section{RESULTS}

\section{PSAT1 was significantly overexpressed in MM cells}

The mRNA and protein expression levels of PSAT1 were measured in MM cell lines (LP-1, $\mathrm{NCl}-\mathrm{H} 929$, and U266) and control cells by realtime quantitative PCR and western blotting, respectively. Results showed that the expression of PSAT1 mRNA was markedly increased in MM cell lines when compared with control cells. (Figure 1A). Western blotting analysis showed consistent results (Figure $1 \mathrm{~B}$ ). Especially, in LP1 cells, PSAT1 mRNA levels were higher than in the other MM cell lines, NCl-H929, and U266, which was thus used in the subsequent analysis.

\section{Downregulation of PSAT1 inhibited proliferation of MM cells}

To explore the function of PSAT1 in the development of $\mathrm{MM}$, the recombinant vectors containing control (shNC) or PSAT1 small hairpin RNA (shPSAT1) were transfected into LP-1 cells, 
and the transfection efficiency was verified. As expected, PSAT1 was significantly downregulated in LP-1 cells that transfected with shPSAT1 when compared with that transfected with shNC (Figure 2 A). This result was also showed from the western blotting results (Figure 2 B). CCK-8 assay demonstrated that downregulation of PSAT1inhibited the proliferation of LP-1 cells that transfected with shPSAT1 when compared with that transfected with shNC (Figure $2 \mathrm{C}$ ).

To determine the effects of PSAT1 on MM cell apoptosis, the protein levels of $\mathrm{Bcl}-2$, Bax, and cleaved caspase-3(all apoptosis-related proteins) in LP-1 cells were investigated. Downregulation of PSAT1, decreased Bcl-2 expression whereas significantly increased the expression levels of apoptosis-associated proteins, Bax and cleaved caspase-3 in LP-1 cells (Figure 2 D).
A

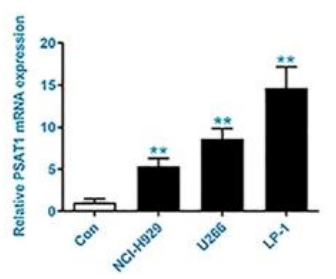

B

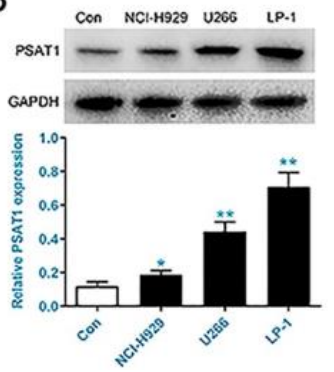

Figure 1: The mRNA and protein expression level of PSAT1 in MM cells. (A) mRNA level of PSAT1 was evaluated in MM cells by qPCR. (B) PSAT1 protein expression level was evaluated in MM cells by western blotting; ${ }^{* *} p<0.01$
A

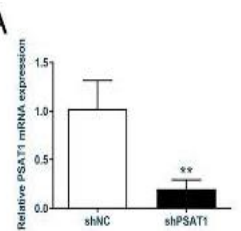

C

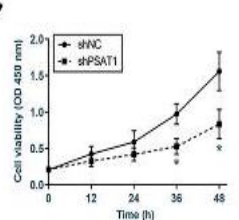

B

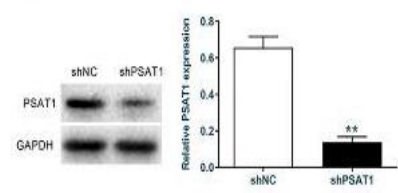

D

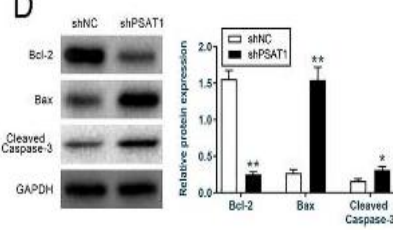

Figure 2: Effect of downregulation of PSAT1 on MM cell proliferation. (A) PSAT1 mRNA levels were determined using qPCR. (B) Protein expression of PSAT1 was measured by western blotting. (C) Cell viability was measured using the CCK-8 assay. (D) Protein expression levels of $\mathrm{Bcl}-2$, Bax and cleaved caspased-3 were measured using western blotting; ${ }^{*} p$ $<0.05,{ }^{* *} p<0.01$

\section{Upregulation of PSAT1 promotes proliferation} of MM cells

The recombinant plasmids, pcDNA3. 1-PSAT1 and pcDNA3.1-NC, were transfected into LP1 cells, and the transfection efficiency was verified by $\mathrm{qPCR}$. The results showed that PSAT1 was significantly upregulated in pcDNA 3.1-PSAT1-transfected cells when compared to pcDNA3.1-NC-transfected cells (Figure $3 \mathrm{~A}$ ). Western blotting results showed similar results (Figure $3 \mathrm{~B}$ ). Next, the proliferation of LP-1 cells was assessed using CCK-8 assay, and the results revealed that upregulation of PSAT1 enhanced cell proliferation as compared to shNC group (Figure $3 \mathrm{C}$ ). Furthermore, the mRNA level of Bcl-2 was increased significantly, whereas the mRNA levels of Bax and cleaved caspase-3 were significantly decreased (Figure $3 \mathrm{D}$ ) in LP-1 cells.
A

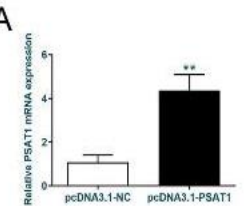

C

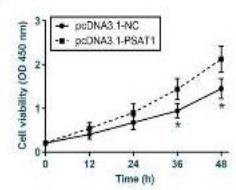

B

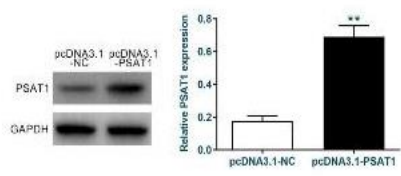

D

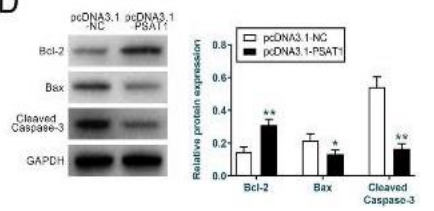

Figure 3: Effects of PSAT1 overexpression on the proliferation of MM cells. (A) The PSAT1 mRNA levels were assessed using qPCR. (B) PSAT1 protein levels were examined by western blotting. (C) Cell viability was measured using CCK-8 assay. (D) The protein expression levels of Bcl-2, Bax, and cleaved caspased-3 were measured by western blotting; ${ }^{*} p<$ $0.05,{ }^{* *} p<0.01$

PSAT1 modulated the proliferation of LP-1 cells via PI3K/AKT signaling

To further reveal the underlying mechanism, the protein expression levels of $\mathrm{p}-\mathrm{PI} 3 \mathrm{~K}$ and $\mathrm{p}-\mathrm{AKT}$ were seriously suppressed by ShPSAT1 in LP-1 cells, whereas no obvious differences were observed in the protein levels of PI3K and AKT (Figure 4).

As a downstream component of PI3K/AKT pathway, cyclin D1 is a key intracellular mediator of extracellular mitogens and may promote cell proliferation through the modulation of the G1 phase of the cell cycle[14,15]. Thus, the expression of cyclinD1 in shPSAT1-expressing LP-1 cells was examined, and the results 
showed that cyclin D1 was downregulated by shPSAT1 (Figure 4).

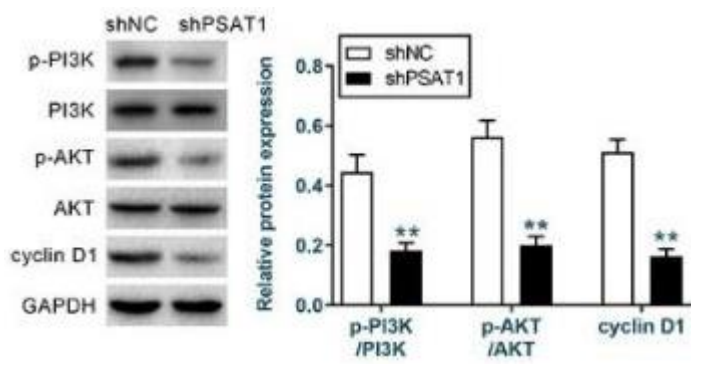

Figure 4: PI3K/AKT/cyclinD1 pathway was regulated by PSAT1.Molecular components of $\mathrm{PI} 3 \mathrm{~K} / \mathrm{AKT} /$ cyclinD1 pathway were measured by western blotting; ${ }^{* *} p<0.01$

\section{DISCUSSION}

Symptomatic plasma cell myeloma, also known as $\mathrm{MM}$, is considered a plasma cell malignancy. Due to the complex clinical symptoms of MM, its treatment is a great challenge. Recent studies have shown that promising treatments for MM are chemotherapeutic agents that can target and kill cancer cells directly. However, it frequently results in the rapid acquisition of drug resistance [16]. Although the pathogenesis of MM remains poorly understood, therapeutic regimens are considered a promising therapeutic strategy.

In this study, it was found that PSAT1 was overexpressed in $\mathrm{MM}$ cell. The upregulation of PSAT1promoted the proliferation of MM cells while downregulation of PSAT1 showed the opposite effect. These results indicate the potential role of PSAT1 in regulating $\mathrm{MM}$ cell proliferation. The PI3K/AKT pathway has been found to play a significant role in tumorigenesis and cancer development [17]. Signals from PI3K to the serine/threonine protein kinase AKT mediate cellular processes such as cell cycle, apoptosis, and cell survival via cyclin D1, p21, $\mathrm{Bcl}-2$, and mTOR [18]. During these cellular processes, synthesis of AKT requires PSAT1related serine biosynthesis. Thus, the protein components of PI3K/AKT pathway were examined in this study using western blotting.

A significant decrease in the expression levels of $\mathrm{p}-\mathrm{PI} \mathrm{K}$ and $\mathrm{p}-\mathrm{AKT}$ in shPSAT1-transfected MM cells were observed. These results supported the hypothesis that PSAT1 exerted an important role in the development of MM by PI3K/Akt signaling pathway. In addition, the levels of the cell cycle biomarker, cyclin D1, were also reduced in shPSAT1-transfected LP-1 cells, suggesting limited cell division cycles. However, additional downstream components of PSAT1, such as
JNK/ERK, which are well-known modulators of tumorigenesis [19], have not yet been identified, but this needs to be analyzed in a future study.

\section{CONCLUSION}

The results of this study reveal that PSAT1 is significantly upregulated in MM cells and plays a novel role in regulating MM cell proliferation, at least partially via PI3K/AKT/cyclin D1 pathway. Thus, PSAT1 may serve as a molecular biomarker as well as a new potential therapeutic target for MM therapy.

\section{DECLARATIONS}

\section{Acknowledgement}

This study was supported by The National Natural Scientific Foundation of China (Grant no. 81703888).

\section{Conflict of interest}

No conflict of interest is associated with this work.

\section{Contribution of authors}

We declare that this work was done by the authors named in this article and all liabilities pertaining to claims relating to the content of this article will be borne by the authors.

\section{Open Access}

This is an Open Access article that uses a funding model which does not charge readers or their institutions for access and distributed under the terms of the Creative Commons Attribution License (http://creativecommons.org/licenses/by/ 4.0) and the Budapest Open Access Initiative (http://www.budapestopenaccessinitiative.org/rea d), which permit unrestricted use, distribution, and reproduction in any medium, provided the original work is properly credited.

\section{REFERENCES}

1. $X u$ T, Yang $W$, Chen L, Gao G. What are the implications of cost for myeloma therapy? Expert Rev Hematol 2019; 12(12): 1005-1009.

2. Barber FD. Multiple Myeloma Early Recognition by Primary Care Nurse Practitioners. J Nurse Pract; 2(10): 665-672.

3. Kazandjian D: Multiple myeloma epidemiology and survival: A unique malignancy. In: Semin Oncol: 2016. Elsevier: 676-681. 
4. Levin A, Hari P, Dhakal B. Novel biomarkers in multiple myeloma. Transl Res 2018; 201:49-59.

5. Gandolfi S, Laubach JP, Hideshima $T$, Chauhan $D$, Anderson KC, Richardson PG. The proteasome and proteasome inhibitors in multiple myeloma. Cancer Metastasis Rev 2017; 36(4): 561-584.

6. De Marchi T, Timmermans MA, Sieuwerts AM. Phosphoserine aminotransferase 1 is associated to poor outcome on tamoxifen therapy in recurrent breast cancer. Sci Rep 2017; 7(1): 2099.

7. Fu Q, Gao Y, Yang F, Mao T, Sun Z, Wang H, Song B, Li $X$. Suppression of microRNA-454 impedes the proliferation and invasion of prostate cancer cells by promoting $\mathrm{N}$-myc downstream-regulated gene 2 and inhibiting WNT/ $\beta$-catenin signaling. Biomed Pharmacother 2018; 97(120-127.

8. Metcalf S, Dougherty S, Kruer T, Hasan N, Biyik-Sit R, Reynolds L, Clem BF. Selective loss of phosphoserine aminotransferase 1 (PSAT1) suppresses migration, invasion, and experimental metastasis in triple negative breast cancer. Clin Exp Metastasis 2020; 37(1): 187197.

9. Possemato R, Marks KM, Shaul YD, Pacold ME, Kim D, Birsoy K, Sethumadhavan S, Woo HK, Jang HG, Jha $A K$ et al. Functional genomics reveal that the serine synthesis pathway is essential in breast cancer. Nature 2011; 476(7360): 346-350.

10. Qian C, Xia Y, Ren Y, Yin Y, Deng A. Identification and validation of PSAT1 as a potential prognostic factor for predicting clinical outcomes in patients with colorectal carcinoma. Oncol lett 2017; 14(6): 8014-8020.

11. Wei Z, Song J, Wang G, Cui X, Zheng J, Tang Y, Chen $X$, Li J, Cui L, Liu C-Y. Deacetylation of serine hydroxymethyl-transferase 2 by SIRT3 promotes colorectal carcinogenesis. Nat Commun 2018; 9(1): 116.

12. Gao $S$, Ge A, Xu S, You Z, Ning S, Zhao Y, Pang D. PSAT1 is regulated by ATF4 and enhances cell proliferation via the GSK3beta/beta-catenin/cyclin D1 signaling pathway in ER-negative breast cancer. J Exp Clin Canc Res: CR 2017; 36(1): 179.

13. Kurien BT, Scofield RH: Western blotting: an introduction. In: Western Blotting. Springer; 2015: 17-30.

14. Guo L, Liang Z, Zheng C, Liu B, Yin Q, Cao Y, Yao J. Leucine affects $\alpha$-amylase synthesis through PI3K/AktmTOR signaling pathways in pancreatic acinar cells of dairy calves. J Agric Food Chem 2018; 66(20): 51495156.

15. Chen H, Zhou L, Wu X, Li R, Wen J, Sha J, Wen X. The PISKJAKT pathway in the pathogenesis of prostate cancer. Front Biosci (Landmark Ed) 2016; 21(10841091.

16. John RR, Malathi N, Ravindran C, Anandan S. Mini review: Multifaceted role played by cyclin D1 in tumor behavior. Indian J Dent Res 2017; 28(2): 187.

17. Sherr CJ. G1 phase progression: cycling on cue. Cell 1994; 79(4): 551-555.

18. Zhou P, Jiang W, Zhang YJ, Kahn SM, Schieren I, Santella RM, Weinstein IB. Antisense to cyclin D1 inhibits growth and reverses the transformed phenotype of human esophageal cancer cells. Oncogene 1995; 11(3): 571-580.

19. Wang TC, Cardiff RD, Zukerberg L, Lees E, Arnold A, Schmidt EV. Mammary hyperplasia and carcinoma in MMTV-cyclin D1 transgenic mice. Nature 1994; 369(6482): 669-671.

20. Musgrove EA, Lee C, Buckley MF, Sutherland RL. Cyclin $D 1$ induction in breast cancer cells shortens $G 1$ and is sufficient for cells arrested in $\mathrm{G} 1$ to complete the cell cycle. P Natl Acad Sci USA 1994; 91(17): 8022-8026.

21. Tay KC, Tan LT, Chan CK, Hong SL, Chan KG, Yap WH, Pusparajah P, Lee LH, Goh BH. Formononetin: A Review of Its Anticancer Potentials and Mechanisms. Front Pharmacol 2019. 